\title{
Recovery and recurrence of left ventricular systolic dysfunction in patients with idiopathic dilated cardiomyopathy
}

\author{
Jeonggeun Moon MD, Young-Guk Ko MD, Namsik Chung MD, Jong-Won Ha MD, \\ Seok-Min Kang MD, Eui-Young Choi MD, Se-Joong Rim MD
}

\begin{abstract}
J Moon, Y-G Ko, N Chung, et al. Recovery and recurrence of left ventricular systolic dysfunction in patients with idiopathic dilated cardiomyopathy. Can J Cardiol 2009;25(5):e147-e150.
\end{abstract}

BACKGROUND: Some patients with nonischemic left ventricular (LV) systolic failure recover to have normal LV systolic function. However, few studies on the rates of recovery and recurrence have been reported, and no definitive indicators that can predict the recurrence of LV dysfunction in recovered idiopathic dilated cardiomyopathy (IDCMP) patients have been determined. It was hypothesized that patients who recovered from nonischemic LV dysfunction have a substantial risk for recurrent heart failure. METHODS: Forty-two patients (32 men) with IDCMP (mean $[ \pm$ SD] age $56.9 \pm 8.7$ years) who recovered from systolic heart failure (LV ejection fraction [LVEF] of $26.5 \pm 6.9 \%$ at initial presentation) to a near-normal state (LVEF of $40 \%$ or greater, and a $10 \%$ increase or greater in absolute value) were monitored for recurrence of LV systolic dysfunction. Patients with significant coronary artery disease were excluded. Patients were monitored for $41.0 \pm 26.3$ months after recovery (LVEF $53.4 \pm 7.6 \%$ ) from LV dysfunction. RESULTS: LV systolic dysfunction reappeared (LVEF $27.5 \pm 8.1 \%$ ) during the follow-up period in eight of 42 patients (19.0\%). No significant difference between the groups with or without recurrent heart failure was observed in the baseline clinical and echocardiographic characteristics. However, more patients in the recurred IDCMP group than those in the group that maintained the recovery state had discontinued antiheart failure medication $(62.5 \%$ versus $5.9 \%, \mathrm{P}<0.05)$.

CONCLUSIONS: LV dysfunction recurs in some patients with reversible IDCMP. The recurrence was significantly correlated with the discontinuation of antiheart failure drugs. The results suggest that continuous medical therapy may be mandatory in patients who recover from LV systolic dysfunction.

Key Words: Congestive heart failure; DCMP; Prognosis
La récupération et la récurrence de la dysfonction systolique ventriculaire chez les patients atteints d'une myocardiopathie dilatée idiopathique

\begin{abstract}
HISTORIQUE : Certains patients atteints d'une insuffisance systolique ventriculaire gauche $(\mathrm{VG})$ non ischémique récupèrent et retrouvent une fonction systolique VG normale. Cependant, il existe peu d'études sur les taux de récupération et de récurrence, et on n'a déterminé aucun indicateur définitif pour prévenir une récurrence de la dysfonction VG chez des patients qui se sont remis d'une myocardiopathie dilatée idiopathique (MCDI). Il a été postulé que les patients qui ont récupéré d'une dysfonction VG non ischémique courent un risque important d'insuffisance cardiaque récurrente. MÉTHODOLOGIE : Quarante-deux patients (32 hommes) ayant une MCDI (âge moyen [ $\pm E ́ T$ ] de $56,9 \pm 8,7$ ans) qui ont récupéré d'une insuffisance cardiaque systolique (fraction d'éjection VG [FÉVG] de $26,5 \pm 6,9 \%$ à la présentation initiale) jusqu'à retrouver un état quasinormal (FÉVG supérieure à au moins $40 \%$ et augmentation d'au moins $10 \%$ en valeur absolue) ont été suivis afin de surveiller toute récurrence de la dysfonction systolique VG. Les patients atteints d'une coronaropathie importante ont été exclus. Les patients ont été suivis pendant 41,0 $\pm 26,3$ mois après avoir récupéré (FÉVG de 53,4 7,6 \%) de la dysfonction VG.

RÉSULTATS : La dysfonction systolique VG a refait son apparition (FÉVG $27,5 \pm 8,1 \%)$ pendant la période de suivi chez huit des 42 patients $(19,0 \%)$. On n'a observé aucune différence significative entre les groupes avec ou sans insuffisance cardiaque récurrente dans les caractéristiques cliniques et échocardiographiques de départ. Cependant, plus de patients du groupe ayant eu une récurrence de la MCDI que de celui ayant maintenu leur état de récupération avaient arrêté de prendre leurs médicaments contre l'insuffisance cardiaque $(62,5 \%$ par rapport à $5,9 \%, \mathrm{P}<0,05)$.

CONCLUSIONS : La dysfonction VG récidive chez certains patients présentant une MCDI réversible. La récurrence était corrélée de manière significative avec l'arrêt des médicaments contre l'insuffisance cardiaque. Selon les résultats, une médicothérapie continue pourrait être impérative chez les patients qui se rétablissent d'une dysfonction systolique VG.
\end{abstract}

In some patients with congestive heart failure, left ventricular (LV) systolic dysfunction improves, which is accompanied by improvements in both clinical symptoms and hemodynamics (1-7). Some cases of idiopathic dilated cardiomyopathy (IDCMP) and tachycardia-induced cardiomyopathy (TIC) are examples that show improvement of LV systolic function (8-11). Congestive heart failure caused by systemic metabolic factors, such as sepsis, hypocalcemia, hypothyroidism, pheochromocytoma and peripartum cardiomyopathy, is another example. Improvement of LV systolic function may also be observed after treatment with interferon and amphotericin B (12-17).

However, neither the clinical course of the nonischemic left heart failure nor clinical guidelines on the management of patients who recover from left heart failure have been established. In the present study, the clinical progress of patients who recovered from congestive heart failure caused by nonischemic LV systolic dysfunction was investigated.

\section{METHODS}

Patients with congestive heart failure accompanied by LV systolic dysfunction were selected retrospectively. Only patients whose symptoms were relieved by medication during the past 13 years were included in the study. Patients were monitored by echocardiography after recovered LV systolic dysfunction was confirmed by echocardiography. Patients with myocardial failure caused by coronary artery disease, hypertension, acute myocarditis, stress-induced cardiomyopathies, and cardiomyopathies accompanied by metabolic diseases or endocrine disorders were excluded.

Division of Cardiology, Department of Internal Medicine, Yonsei University College of Medicine, Seoul, South Korea

Correspondence and reprints: Dr Se-Joong Rim, Cardiology Division, Yongdong Severance Hospital, 146-92 Dogok-dong, Kangnam-gu, Seoul,

135-270, Republic of Korea. Telephone 82-2-2019-3310, fax 82-2-3463-3882, e-mail sejoong@yuhs.ac

Received for publication August 6, 2007. Accepted March 22, 2009 
TABLE 1

\section{Clinical characteristics of patients}

\begin{tabular}{|c|c|c|c|c|c|c|}
\hline \multicolumn{5}{|c|}{ Number of patients } & \multicolumn{2}{|c|}{42} \\
\hline \multicolumn{5}{|c|}{ Age, years, mean \pm SD } & \multicolumn{2}{|c|}{$56.9 \pm 8.7$} \\
\hline \multicolumn{7}{|c|}{ Sex, n (\%) } \\
\hline \multicolumn{5}{|c|}{ Male } & \multicolumn{2}{|c|}{$32(76)$} \\
\hline \multicolumn{5}{|c|}{ Female } & \multicolumn{2}{|c|}{$10(24)$} \\
\hline \multicolumn{7}{|c|}{ Initial New York Heart Association class, n (\%) } \\
\hline \multicolumn{5}{|l|}{ III } & \multicolumn{2}{|c|}{$33(79)$} \\
\hline \multicolumn{5}{|l|}{ IV } & \multicolumn{2}{|c|}{$9(21)$} \\
\hline \multicolumn{5}{|c|}{ Initial EF, \%, mean \pm SD } & \multicolumn{2}{|c|}{$26.5 \pm 6.9$} \\
\hline \multicolumn{7}{|c|}{ Prescribed antiheart failure medication, $\mathrm{n}(\%)$} \\
\hline \multicolumn{5}{|c|}{ ACE inhibitors or ARBs, no beta-blockers } & \multicolumn{2}{|c|}{$22(52)$} \\
\hline \multicolumn{5}{|c|}{ ACE inhibitors or ARBs, plus beta-blockers } & \multicolumn{2}{|c|}{$20(48)$} \\
\hline \multicolumn{5}{|c|}{ Time to recovery of EF, months, mean \pm SD } & \multicolumn{2}{|c|}{$15.4 \pm 11.8$} \\
\hline \multicolumn{5}{|c|}{ EF at the time of recovery, $\%$, mean $\pm S D$} & \multicolumn{2}{|c|}{$53.4 \pm 7.6$} \\
\hline \multirow{2}{*}{\multicolumn{7}{|c|}{$\begin{array}{l}\text { ACE Angiotensin-converting enzyme; ARB Angiotensin II receptor blocker; Ef } \\
\text { Ejection fraction } \\
\text { TABLE } 2 \\
\text { Clinical characteristics of patients with recurrent heart } \\
\text { failure }(\mathbf{n}=\mathbf{8})\end{array}$}} \\
\hline & & & & & & \\
\hline Sex & $\begin{array}{c}\text { Age, } \\
\text { years }\end{array}$ & $\begin{array}{l}\text { Initial } \\
\text { EF, \% }\end{array}$ & $\begin{array}{l}\text { Time to } \\
\text { recovery, } \\
\text { months }\end{array}$ & $\begin{array}{c}\text { EF after } \\
\text { recovery, } \\
\%\end{array}$ & $\begin{array}{c}\text { Time to } \\
\text { recurrent } \\
\text { heart failure, } \\
\text { months }\end{array}$ & $\begin{array}{c}\text { EF after } \\
\text { recurrent } \\
\text { heart failure, } \\
\%\end{array}$ \\
\hline M & 47 & 34 & 18 & 61 & 37 & 21 \\
\hline $\mathrm{F}$ & 56 & 33 & 12 & 49 & 11 & 31 \\
\hline M & 38 & 24 & 8 & 47 & 46 & 21 \\
\hline$M$ & 76 & 39 & 25 & 58 & 69 & 38 \\
\hline $\mathrm{F}$ & 56 & 26 & 12 & 41 & 46 & 21 \\
\hline$M$ & 36 & 28 & 21 & 51 & 21 & 31 \\
\hline$M$ & 64 & 27 & 1 & 41 & 96 & 29 \\
\hline $\mathrm{F}$ & 63 & 20 & 4 & 47 & 33 & 28 \\
\hline
\end{tabular}

EF Ejection fraction; F Female; $M$ Male

Forty-two patients with reversible nonischemic LV systolic failure were enrolled. Patients had undergone clinical follow-up and echocardiography at Severance Hospital (Seoul, Republic of Korea) during the past 13 years (since 1995). Originally, there were 86 patients with reversible nonischemic LV systolic failure who met the enrolment criteria of the present study. However, 44 patients were excluded because they had not been followed up, had died without leaving behind any medical records or could not be contacted.

The following information was confirmed by chart review: the onset of the first symptoms; symptoms and findings when congestive heart failure was diagnosed; initial echocardiography findings that showed LV systolic dysfunction and other findings observed by electrocardiography, $\mathrm{x}$-ray and coronary angiography; etiology of dilated cardiomyopathy (DCMP); echocardiographic findings once LV function had recovered after proper medical treatment; and clinical data that included evaluation of symptoms and echocardiographic findings at the time of subsequent follow-up visits.

LV systolic dysfunction was defined as an ejection fraction (EF) of less than $40 \%$ by echocardiography. The recovery of LV systolic function was defined as recovery of the EF to a level of $40 \%$ or greater and a net increase in $\mathrm{EF}$ of $10 \%$ or greater.

\section{Statistical data}

All values in the present study are presented as mean \pm SD. Statistical data were processed by SPSS (Windows Release 13.0; SPSS Inc, USA) and considered to be statistically significant when $\mathrm{P}<0.05$. The unpaired $t$ test and $\chi^{2}$ test were used to compare variables between the groups. The dichotomizing logistic regression procedure and the
TABLE 3

Clinical and echocardiographic characteristics in patient groups with or without recurrent heart failure

\begin{tabular}{|c|c|c|c|}
\hline Characteristic & $\begin{array}{c}\text { Patients } \\
\text { without } \\
\text { recurrent } \\
\text { heart failure } \\
(n=34)\end{array}$ & $\begin{array}{l}\text { Patients with } \\
\text { recurrent } \\
\text { heart failure } \\
\quad(n=8)\end{array}$ & $\mathbf{P}$ \\
\hline Men:Women, $\mathrm{n}$ & $3.89: 1$ & $1.67: 1$ & 0.570 \\
\hline Age, years & $56.4 \pm 13.0$ & $51.2 \pm 12.7$ & 0.754 \\
\hline Initial NYHA class & $3.2 \pm 0.3$ & $3.2 \pm 0.4$ & 0.369 \\
\hline Initial Framingham score & $4.7 \pm 1.6$ & $4.6 \pm 1.1$ & 0.803 \\
\hline Patient with initial MR ( $\geq$ grade 2$), \mathrm{n}(\%)$ & $19(46.3)$ & $2(22.2)$ & 0.131 \\
\hline Initial EF, \% & $27.5 \pm 7.3$ & $24.8 \pm 6.8$ & 0.109 \\
\hline Initial LVEDD, mm & $62.7 \pm 6.8$ & $65.0 \pm 8.7$ & 0.734 \\
\hline Initial LVESD, mm & $53.0 \pm 7.8$ & $54.6 \pm 7.6$ & 0.369 \\
\hline EF improvement, $\Delta \%$ & $23.5 \pm 9.7$ & $25.6 \pm 6.2$ & 0.531 \\
\hline EF after recovery, \% & $53.9 \pm 8.0$ & $47.5 \pm 6.8$ & 0.301 \\
\hline LVEDD after recovery, $\mathrm{mm}$ & $51.3 \pm 4.9$ & $58.5 \pm 9.9$ & 0.388 \\
\hline LVEDD improvement, $\Delta \%$ & $12.7 \pm 4.7$ & $11.6 \pm 5.5$ & 0.263 \\
\hline LVESD after recovery, $\mathrm{mm}$ & $36.4 \pm 4.8$ & $47.5 \pm 11.3$ & 0.066 \\
\hline LVESD improvement, $\Delta \%$ & $29.3 \pm 8.1$ & $16.7 \pm 7.8$ & 0.057 \\
\hline Time to recovery, months & $16.2 \pm 14.2$ & $14.7 \pm 9.3$ & 0.523 \\
\hline $\begin{array}{l}\text { Patient who stopped antiheart failure } \\
\text { medication after recovery, } \mathrm{n}(\%)\end{array}$ & $2(5.9)$ & $5(62.5)$ & $0.020^{*}$ \\
\hline Patient prescribed beta-blocker, n (\%) & $21(67.7)$ & $2(25)$ & 0.114 \\
\hline
\end{tabular}

Values are presented as mean $\pm S D$ unless stated otherwise. ${ }^{*} P<0.05$ indicates significance. $\triangle \%$ Percentage change; EF Ejection fraction; LVEDD Left ventricular end-diastolic dimension; LVESD Left ventricular end-systolic dimension; MR Mitral regurgitation; NYHA New York Heart Association

Kaplan-Meier test were used to analyze factors that significantly affected the prognosis of the groups.

Patient characteristics

\section{RESULTS}

Thirty-two men $(76 \%)$ and 10 women $(24 \%)$ with a mean age of $56.9 \pm 8.7$ years were reviewed. Thirty-three patients $(79 \%)$ were New York Heart Association class III and nine patients (21\%) were class IV when they were diagnosed with congestive heart failure.

LV systolic dysfunction (LVEF less than 40\%) was confirmed in all patients by echocardiography (mean EF $26.5 \pm 6.9 \%$ ). All of the patients were treated with angiotensin-converting enzyme inhibitors or angiotensin receptor antagonists. Beta-blockers were added to the regimen in 20 patients $(48 \%)$. All patients showed improved symptoms and LV contractile function after treatment. The EF at the time of improvement was $53.4 \pm 7.6 \%$ (determined by echocardiography) and the net increase was $24.7 \pm 8.7 \%$ from the initial value. The mean time to show improved symptoms and echocardiographic findings was $15.4 \pm 11.8$ months. Patients were monitored for $41.0 \pm 26.3$ months after improvement was confirmed, meaning that they were followed up for $48.4 \pm 15.3$ months from the time of their initial diagnosis of heart failure (Table 1).

Progress after clinical improvement and reversible recovery Recovery from congestive heart failure and LV contractile dysfunction was maintained in 34 patients (80.9\%) with a mean EF of $53.9 \pm 8.0 \%$. The improved states were maintained for $32.3 \pm 13.9$ months. However, LV systolic dysfunction recurred in eight patients (19.0\%) whose mean EF was $27.5 \pm 8.1 \%$. The recurrence occurred $44.9 \pm 33.6$ months after recovery (Table 2$)$.

\section{Intergroup comparison}

The clinical characteristics of the groups with or without recurrent heart failure are compared in Table 3. Maintenance of antiheart failure 
TABLE 4

Factors that influence recurrent left ventricular systolic dysfunction

\begin{tabular}{lcc}
\hline Influencing factors & OR & P \\
\hline Sex & 0.881 & 0.34 \\
Before recovery & & \\
$\quad$ Age & 0.997 & 0.995 \\
Causative disease & 4.461 & 0.344 \\
New York Heart Association class & 0.917 & 0.364 \\
Framingham score & 0.749 & 0.309 \\
Ejection fraction & 0.861 & 0.212 \\
LVEDD & 1.113 & 0.168 \\
LVESD & 1.009 & 0.126 \\
Mitral regurgitation ( grade 2) & 0.063 & 0.126 \\
Concomitant beta-blocker usage & 0.361 & 0.407 \\
Time to recovery & 0.861 & 0.434 \\
After recovery & & \\
Ejection fraction & 0.749 & 0.401 \\
LVEDD & 1.313 & 0.826 \\
LVESD & 0.695 & 0.146 \\
Cessation of antiheart failure & 26.667 & 0.007 * \\
medications & $(95 \%$ Cl & \\
\hline
\end{tabular}

${ }^{*} P<0.05$ indicates significance. LVEDD Left ventricular end-diastolic dimension; LVESD Left ventricular end-systolic dimension

medication after recovery was the only parameter that was significantly different between the groups. Among patients who developed recurrence of left heart failure, three patients discontinued their medications as recommended by their physician and two patients on their own accord. Heart failure relapsed 32.2 \pm 7.6 months after they discontinued the medication. In the group without recurrence, two patients discontinued their medications as recommended by their physician and no evidence of recurrence was detected at nine and 72 months after discontinuation. Maintenance of the medication was proven to be a significant factor in a multiple regression analysis that compared risk factors such as sex, age, severity of heart failure symptoms at the time of diagnosis, EF, time to recovery and antiheart failure medication $(\mathrm{P}<0.05)$ (Table 4). The groups with or without maintenance of medication after recovery were compared (Figure 1), and the group with maintained medication had significantly fewer recurrences $(\mathrm{P}=0.021)$.

\section{DISCUSSION}

When following congestive heart failure patients with LV systolic dysfunction, it has often been observed that some patients recover and develop normal LV systolic function $(9,10)$. This phenomenon is limited not only to ischemic heart diseases and myocarditis, but also to IDCMP, DCMPs secondary to certain drugs and alcohol abuse, TIC and peripartum cardiomyopathies. However, few studies on recovery rates have been reported, and the indicators that predict the possibility of recovery in DCMP patients have not been identified.

Some patients with IDCMP develop recurrence of LV systolic failure after recovery. In a recent study of 24 TIC patients, Nerheim et al (11) reported that patients showed improvement in both symptoms and LV function 5.8 \pm 4.8 months after tachycardia was controlled by medical therapy or electrocatheter ablation. However, in five patients, LV dysfunction rapidly reappeared when tachycardia redeveloped. The authors suggested that the hearts of patients with TIC might develop ultrastructural changes that make the heart more vulnerable to recurrent heart failure, even though symptoms and LV function have improved. In fact, they observed degenerative changes such as interstitial fibrosis and edema in two patients with TIC on endomyocardial biopsy. Ultrastructural changes have also been proven in animal experiments. Katstura et al (18) induced TIC in canines and observed fibrosis of cardiac muscle without changes in

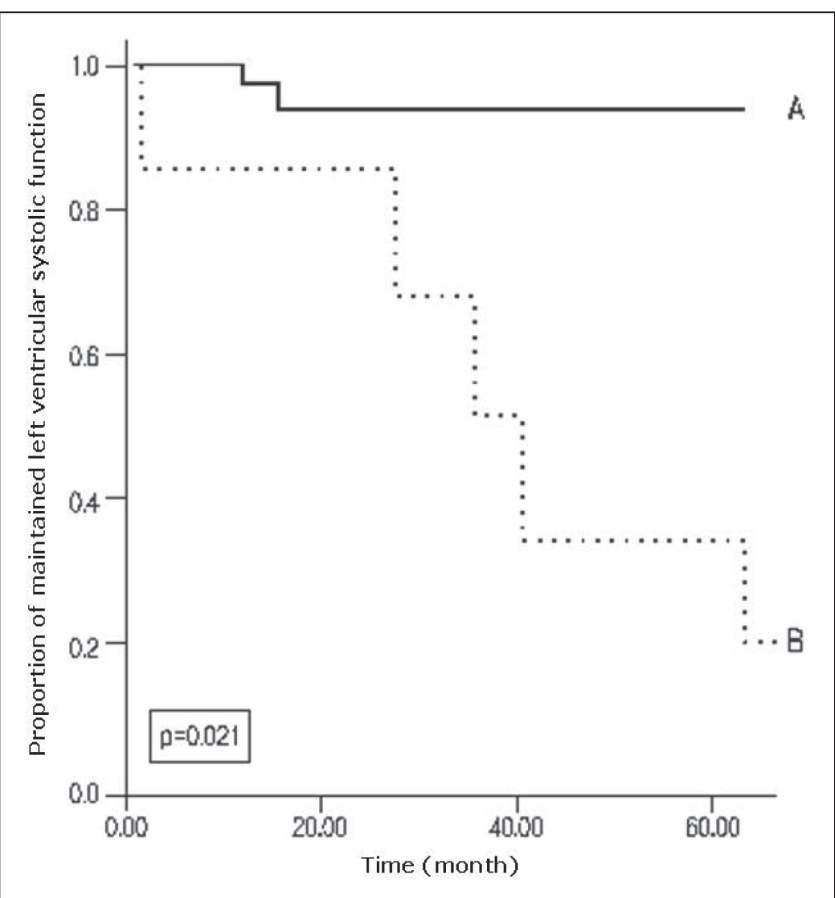

Figure 1) Recurrence of heart failure (Kaplan-Meier curve). A Patients who maintained their antiheart failure medication. B Patients who discontinued their antiheart failure medication

heart weight, which suggested that the heart did not have macroscopic changes such as cardiomegaly. Takahashi et al (19) reported an increase of beta-actin, gamma-actin and alpha-tubulin in animal models of TIC. These results suggested that LV systolic function alone may not be sufficient as a surrogate marker of remodeling and clinical improvement from congestive heart failure. In addition, improved LV contractile function evaluated by echocardiography cannot be used as an indicator of recovery from TIC (20).

Improvement in congestive heart failure symptoms and recovery from LV systolic dysfunction evaluated by echocardiography cannot be regarded as a complete recovery from IDCMP. We assumed that a history of congestive heart failure itself could be a risk factor for recurrent heart failure and hypothesized that ultrastructural changes of cardiac muscle were associated. In fact, two patients in the present study were subjected to endomyocardial biopsy, and ultrastructural changes including interstitial fibrosis were detected. These findings were not observed in all patients, but they could affect vulnerability to stimuli, result in reduced cardiac contractility, and be a risk factor for recurrent heart failure. Additional studies are needed to prove this hypothesis.

Few studies have been conducted on whether IDCMP patients who recovered from congestive heart failure can maintain improvement in the long term or whether LV dysfunction will recur. Because we often find that DCMP patients do recover, it may be very important to understand their clinical progress. In the present study, we confirmed that patients who recovered from LV failure developed recurrent congestive heart failure associated with LV contractile dysfunction, sometimes without any clinically specific reason. Therefore, patients should be continuously monitored in follow-up studies, even after left heart failure recovery. In the recurrent group, recurrence of LV contractile dysfunction was observed $44.9 \pm 33.6$ months after recovery from heart failure. The group whose recovery state was maintained did not show a recurrence of heart failure for a follow-up period of $32.3 \pm 13.9$ months. The follow-up period for this group was relatively short, so we cannot exclude the possibility of subsequent recurrence.

Other questions that should be raised in the management of recovered LV systolic failure are the type and duration of therapy. The 
established protocols of medical therapy for congestive heart failure are suitable for typical chronic heart failure with decreasing heart function, but may not be useful in cases in which heart failure recovers after treatment. However, a decision is needed regarding whether medical therapy should be continued. The current study showed that the recurrence rate of left heart failure was significantly correlated with the discontinuation of antiheart failure drugs, which suggests that continuous medical therapy in recovered IDCMP patients is indicated. Although many studies showed that beta-blockers, angiotensin-converting enzyme inhibitors and angiotensin receptor antagonists were effective in treating congestive heart failure, it is controversial whether the drugs should be administered to patients after recovery of LV dysfunction despite the high cost and adverse effects. More studies are needed on this matter.

The present study has the following limitations: it was performed retrospectively; analyses of biochemical markers, including genetic

\section{REFERENCES}

1. O'Connell JB, Bristow M. Economic impact of heart failure in the United States: Time for a different approach. J Heart Lung Transplant 1999;13:S107.

2. Hunt SA; American College of Cardiology; American Heart Association Task Force on Practice Guidelines (Writing Committee to Update the 2001 Guidelines for the Evaluation and Management of Heart Failure). ACC/AHA guidelines for the evaluation and management of chronic heart failure in the adult. J Am Coll Cardiol 2005;46:e1-82.

3. McLaran CJ, Gersh BJ, Sugrue DD, et al. Tachycardia induced myocardial dysfunction. A reversible phenomenon? Br Heart J 1985;53:323-7.

4. Anselme F, Boyle N, Josephson M. Incessant fascicular tachycardia: A cause of arrhythmia induced cardiomyopathy. Pacing Clin Electrophysiol 1998;21:760-3.

5. Reza M, Hans M, Finn W. New insights into the pathogenesis of dilated cardiomyopathy: Possible underlying autoimmune mechanism and therapy. Autoimmunity Reviews 2004;3:277-84.

6. Sugrue DD, Rodeheffer RJ, Codd MB, et al. The clinical course of idiopathic dilated cardiomyopathy - a population based study. Ann Intern Med 1992;17:117-23.

7. Cetta F, Michels VV. The natural history and spectrum of idiopathic dilated cardiomyopathy including HIV and peripartum cardiomyopathy. Curr Opinion Cardiol 1995;10:332-8.

8. Khanlou H, Paltoo B, Forbes W. Echocardiographic parameters in reversible idiopathic dilated cardiomyopathy. Am J Med Sci 2000;319:366-9.

9. Schwarz F, Mall G, Zebe H, et al. Determinants of survival in patients with congestive cardiomyopathy: Quantitative morphologic findings and LV hemodynamics. Circulation 1984;70:923-8.

10. Mann-Rouillard V, Fishbein MC, Naqvi TZ, Don-Michael TA, Seigel RJ. Echocardiographic normalization of heart size and factors or cytokines, were not included; data from many patients who dropped out during the follow-up period could not be collected, which could have introduced a sampling error; the number of subjects was small; and diastolic function was not included as an echocardiographic parameter. Moreover, the study was initiated before clear criteria for the recovery of heart failure were established. Nevertheless, the present study clearly shows that LV systolic dysfunction can relapse in patients who have recovered from left heart failure. Our data suggest that the discontinuation of antiheart failure drugs after recovery from heart failure is an independent risk factor for recurrence of systolic dysfunction. Continuous follow-up and proper medical therapy should be considered for patients with nonischemic left heart failure. In future studies, genetic analyses, correlation with biochemical markers and responses to various drugs should be determined.

contractility in idiopathic dilated cardiomyopathy. Am J Cardiol 1999;83:131-2.

11. Nerheim P, Birger-Botkin S, Piracha L, Olshansky B. Heart failure and sudden death in patients with tachycardia-induced cardiomyopathy and recurrent tachycardia. Circulation 2004;110:247-52.

12. Kuwata A, Ohashi M, Sugiyama M, Ueda R, Dohi Y. A case of reversible dilated cardiomyopathy after alpha-interferon therapy in a patient with renal cell carcinoma. Am J Med Sci 2002;324:331-4.

13. Danaher PJ, Cao MK, Anstead GM, Dolan MJ, DeWitt CC. Reversible dilated cardiomyopathy related to amphotericin B therapy. J Antimicrob Chemother 2004;53:115-7.

14. Kontani M, Izumiya Y, Shimizu M, et al. Acute reversible myocardial depression associated with sepsis. Intern Med 2003;42:60-5.

15. Avsar A, Dogan A, Tavli T. A rare cause of reversible dilated cardiomyopathy: Hypocalcemia. Echocardiography 2004;21:609-12.

16. Bezdah L, Slimene H, Kammoun M, Haddad A, Belhani A. Hypothyroid dilated cardiomyopathy. Ann Cardiol Angiol 2004;53:217-20.

17. Phillips SD, Warnes CA. Peripartum cardiomyopathy: Current therapeutic perspectives 2004;6:481-8.

18. Katstura J, Zhang X, Liu Y, et al. The cellular basis of pacing induced dilated cardiomyopathy: Myocyte cell loss and myocyte cellular reactive hypertrophy. Circulation 1995;92:2306-17.

19. Takahashi M, Tsutsui H, Kinugawa S, et al. Role of microtubules in the contractile dysfunction of myocytes from tachycardia-induced dilated cardiomyopathy. J Mol Cell Cardiol 1998;30:1047-57.

20. Spinale FG, Tomita M, Zellner JL, et al. Collagen remodeling and changes in LV function during development and recovery from supraventricular tachycardia. Am J Physiol 1991;261:308-18. 